\title{
Universidades, Arqueologia e Paulo Duarte.
}

Pedro Paulo A. Funari*

Aline V. Carvalho**

FUNARI, P.P.A.; CARVALHO, A.V. Universidades, Arqueologia e Paulo Duarte.

R. Museu Arq. Etn., São Paulo, n. 22, p. 89-96, 2012.

Resumo: $\mathrm{O}$ presente artigo almeja analisar a trajetória da Arqueologia acadêmica universitária no Brasil, partindo de uma perspectiva institucional do Estado de São Paulo. Opta-se por uma visão externalista da História da Ciência, inserindo a própria ciência em um contexto social mais amplo. Com esse objetivo, passaremos pela fundação da Universidade de São Paulo e a institucionalização das relações intelectuais com a França, nas décadas de 1930 e 1940; as ações de Paulo Duarte, humanista brasileiro responsável, entre outras realizações, pela fundação do Instituto de Pré-história; o Golpe Militar e seus desdobramentos sobre algumas das práticas da Arqueologia universitária, chegando, por fim, à democratização política nos anos de 1980 e a inserção das pesquisas brasileiras no cenário internacional.

Palavras-chaves: Arqueologia Universitária, História da Ciência e Paulo Duarte.

\section{Introdução}

Arqueologia tem larga tradição no Brasil como Estado Nação (Ferreira 2005), mas seria apenas com a fundação da primeira universidade brasileira, em 1934, que a Arqueologia, pouco a pouco, passaria a ter feições universitárias. A Universidade de São Paulo, fundada em 1934 pela elite paulista, marcou época e continua a ser, no início do século XXI, a mais importante universidade brasileira, segundo

${ }^{*}$ ) Professor Titular, Coordenador do Centro de Estudos Avançados da Unicamp, 〈www.gr.unicamp.br/ceav>

${ }^{(* *}$ Pesquisadora do Núcleo de Estudos e Pesquisas Ambientais, Unicamp; Diretora do Laboratório de Arqueologia Pública (LAP - Nepam/Unicamp) e Coordenadora Associada do Núcleo de Estudos e Pesquisas Ambientais (NEPAM). rankings internacionais ${ }^{1}$. Enquanto as colônias espanholas tiveram suas primeiras universidades no início da colonização, o Brasil apenas teve faculdades isoladas de Direito a partir de 1827, em São Paulo (Largo de São Francisco) e em Olinda, seguidas, com o correr das décadas, de outras de medicina e engenharia. A fundação da Universidade de São Paulo viria a marcar, de maneira indelével, a Arqueologia universitária no país. A criação da instituição, por iniciativa de intelectuais como Paulo Duarte, futuro introdutor da Arqueologia universitária no Brasil, marcava uma ruptura epistemológica e política com a

(1) http://www.timeshighereducation.co.uk/world-university-rankings/2011-2012/top-400.html Data de acesso: 12/06/2012. 
Arqueologia nobiliárquica e aristocrática, mas, também, com a ciência de instituições como Institutos e Museus que não eram universitários e não tinham como tarefa o ensino e a pesquisa (Funari e Menezes 2006).

Marca dessa mudança de perspectiva estava na vinda de intelectuais, professores e pesquisadores a um só tempo, como o jovem Claude Lévi-Strauss, antropólogo que trouxe consigo uma valorização do indígena, com a devida chancela acadêmica, que nunca fora possível antes em um país sem universidades. A universidade, recém-criada no Brasil, contudo, enfrentou, a partir de novembro de 1937, a imposição de uma ditadura, o Estado Novo (1937-1945), que iria levar muitos democratas aos calabouços, à morte e ao exílio. A queda da ditadura, após o retorno dos pracinhas dos campos europeus, em 1945, conduziu ao restabelecimento de liberdades civis, ao retorno dos exilados que sobreviveram, dentre os quais se destacava Paulo Duarte (1899-1984), antigo fundador da Universidade de São Paulo, que voltava imbuído de um humanismo radical: a defesa do indígena, $\mathrm{o}$ homem americano. Duarte, homem que havia, desde o início, apostado tudo na Universidade, decidiu-se por criar a Arqueologia universitária e, para isso, tanto iniciou cursos de difusão quanto buscou trazer arqueólogos universitários que pudessem formar os primeiros arqueólogos acadêmicos brasileiros.

Paul Rivet (1876-1958), grande humanista e fundador do Museu do Homem, em Paris, em 1937, foi a grande inspiração e interlocutor de Paulo Duarte nessa lide (Funari e Silva 2007). Por seu intermédio, aqui vieram os primeiros arqueólogos universitários, em um contexto universitário, para formar acadêmicos. Joseph Emperaire e Annette Laming-Emperaire (1917-1977), nesse influxo, exerceram esse papel essencial, ao formarem os primeiros nativos, cujo nome paradigmático, por vários motivos, foi Niède Guidon (1933-): interiorana, universitária, mulher, que se doutoraria sob a orientação de outro ícone da Arqueologia universitária, André Leroi-Gourhan (1911-1986). Na mesma linha, outro grande atuante na Arqueologia universitária brasileira é André Prous (1944-), aluno de Annette Laming-Emperaire.
O golpe de primeiro de abril de 1964, contudo, viria a afetar os próximos vinte e um anos a vida do país e a trajetória da Arqueologia universitária no país (Funari 1994). Prisões, mortes, cassações e exílio, no âmbito da vida pública, inclusive universitária, marcariam a disciplina (Funari 2002). Apenas com a restauração dos civis em 1985 a liberdade viria a bafejar a Arqueologia universitária, então revigorada pela diversificação da formação acadêmica no Brasil. Nesse quarto de século, a Universidade brasileira expandiu-se de forma exponencial, tanto na graduação, como na pós-graduação. Um país com tradição universitária tão tardia como o Brasil produziu, em poucas décadas, a melhor universidade da América Latina (a Universidade de São Paulo) e a mais produtiva (a Universidade Estadual de Campinas, fundada em 1966). A Arqueologia, surgida como avis rara, prática de poucos, contestada e mesmo vilipendiada em sua defesa da humanidade, tornou-se formação acadêmica sólida, com mestres e doutores formados na própria universidade brasileira. De prática nobiliarquia, fora do âmbito acadêmico, a Arqueologia chega à segunda década do século XXI forte não só como atividade universitária reconhecida no Brasil e no estrangeiro, como relevante para os grupos sociais mais variados e secularmente excluídos, ignorados ou rejeitados.

Neste artigo procuramos apresentar, ainda que de forma breve e introdutória, uma narrativa de alguns aspectos da trajetória universitária da Arqueologia universitária. Dois são os aspectos: como a universidade foi e é importante para o desenvolvimento da Arqueologia no Brasil e como a Arqueologia universitária foi e é importante para a sociedade brasileira. Partimos do pressuposto de uma História da Ciência externalista, ou seja, que vincula as transformações sociais e políticas como fundamento para a compreensão da compreensão científica do mundo. Os movimentos e embates sociais estão na raiz das transformações científicas. Ademais, a Arqueologia, surgida nobiliarquia, pôde tornar-se, com o tempo e como resultado das lutas sociais, não mais arma da opressão, mas de liberdade de indígenas, negros, mulheres, e tantos outros movimentos sociais quanto queiramos. 


\section{A produção acadêmica}

A institucionalização da Arqueologia na Universidade, iniciada com a atuação pioneira de Paulo Duarte e golpeada pela ditadura (19641985), viria a prosperar após a restauração das liberdades, em especial por meio da pós-graduação. O sistema de pós-graduação iniciou-se ainda sob os auspícios dos militares, mas, quando do advento dos civis, ele permitiu o florescimento de uma ciência ao corrente das discussões internacionais e, de alguma forma, relacionada com a sociedade brasileira, ainda que de forma apenas parcial e fragmentária. A produção acadêmica no país passou, de forma gradual e crescente, a contar com mecanismos que buscavam privilegiar o mérito - como pela generalização do sistema de avaliação por pares e o arbítrio externo - e inspirar a inserção internacional. Tais movimentos foram caracterizados pelas contradições inerentes a um processo como esse, em ambiente ainda impregnado pelo regime autoritário e no contexto secular de uma sociedade patrimonial, patriarcal, muito ancorada nas relações de compadrio e de colonização interna e externa.

Houve dois caminhos nessa formação universitária, tanto na Arqueologia, como em todo o sistema de pós-graduação: a formação em programas brasileiros e a titulação no estrangeiro, com a mescla de ambos em muitos casos, pois houve, desde cedo, um incentivo à ida de doutorandos brasileiros para estágios no estrangeiro. A grande maioria dos arqueólogos que seguiram formação em mestrado e doutoramento estudou em instituições brasileiras, sem estágio externo. Essa formação deu-se em programas de pós de áreas afins, como a História e a Antropologia, até o surgimento do primeiro curso de Arqueologia, na Universidade de São Paulo, com o primeiro título obtido em 1990. Essa formação arqueológica em programas variados constitui uma característica marcante da Arqueologia no Brasil, embora também na tradição européia a formação seja em programas de História, História da Arte e Pré-História, assim como nos Estados Unidos predomina a titulação em Antropologia. A Arqueologia universitária brasileira, desde o início, portanto, foi interdisciplinar e aberta ao diálogo entre as ciências.
Uma minoria obteve formação integral ou parcial no estrangeiro. Os órgãos de fomento, tanto no Brasil como em outros países periféricos, sempre tiveram que enfrentar os dilemas da formação nacional ou internacional. $\mathrm{O}$ estudo no próprio país é feito na língua nacional, pode incluir estudantes de origem menos elitista, envolve custos menores, pode atingir um número muito maior de pessoas e facilita a inserção do titulado na sociedade nacional. Por outro lado, a atuação internacional do estudioso tende a ser modesta e os mecanismos de incentivo para isso são precários e pouco efetivos. Corre-se o risco do que se convencionou chamar de caipirismo (conhecido também como científico charro, no México).

Muitos países periféricos, como, em nosso continente, a Argentina e a Colômbia, preferiram enfatizar a formação de seus quadros no estrangeiro, em especial nos Estados Unidos e, de forma secundária, na Europa. Essa opção enfatiza os aspectos elitistas da formação universitária, pois aqueles que conseguem ir ao estrangeiro devem ter tanto poder econômico mesmo quando há bolsas - como, mais ainda, precisam ter um capital cultural que permita tal salto. Como constatou o sociólogo francês Pierre Bourdieu, aprender um idioma estrangeiro é um privilégio de classe, assim como saber como comportar-se em ambientes culturais estranhos. Desta forma, a formação no estrangeiro, mesmo com os efeitos corretivos das bolsas, apresenta vieses. Em seguida, e como conseqüência dessas mesmas características, a formação nos países dominantes leva a processo de fuga de cérebros (brain drain), pois há mecanismos poderosos de atração de jovens pesquisadores dedicados à ciência, como bons salários e, mais ainda, boas condições de trabalho, na forma de laboratórios e possibilidades de pesquisa, pouco disponíveis na periferia. O objetivo de tais políticas, contudo, sempre foi de formar quadros de alta qualificação, bem inseridos na ciência internacional, mas que se dedicassem à ciência em seu país periférico. Esse retorno nem sempre ocorreu e menos ainda a inserção do egresso foi fácil, pois as condições nacionais diferiam tanto das estrangeiras. Ademais, a aceitação dos graduados no estrangeiro, mesmo quando isso 
ocorreu, não foi sem fricções e asperezas, de parte a parte, pois, muitas vezes, os "caipiras" ressentiram-se da arrogância dos egressos do estrangeiro e estes, tantas vezes, não deixaram de arrogar-se uma liderança que consideravam direito seu. Muitos nunca voltaram.

A Arqueologia, nestas circunstâncias, também enviou jovens para estágios no estrangeiro, em geral como parte de sua titulação no Brasil, mas também alguns para toda a formação em potências centrais. Para além de tudo que já se disse sobre as contradições dessa situação, cabe apenas acrescentar que a Arqueologia universitária tanto se beneficiou com "caipiras" e "estrangeiros", como se viu refém dos pontos fortes e débeis de ambas as formações.

A Arqueologia universitária, cada vez mais, nas últimas décadas, produziu resultados notáveis, na forma de dissertações de mestrado, teses de doutoramento, pesquisas de pós-doutoramento, livros e inúmeras outras produções acadêmicas. A publicação de volumes de Arqueologia multiplicou-se, de forma exponencial, desde 1985, resultado, de uma forma ou de outra, do ensino superior. Livros sobre Pré-História, Arqueologia Histórica e uma pletora de temas mais específicos têm sido publicados e reeditados. A produção de obras de apoio didático sobre temas arqueológicos por brasileiros veio a complementar a tradução de livros estrangeiros, de modo que, hoje, temos volumes sobre a Arqueologia Amazônica ou sobre os antigos habitantes do Brasil, mas também sobre questões universais como a respeito da cultura material de gregos e romanos.

A inserção internacional da Arqueologia brasileira também cresceu de forma acentuada nesse período, resultado do ensino superior brasileiro, em grande parte. Livros arqueológicos de brasileiros foram publicados lá fora, tanto sobre temas nacionais, como internacionais ou universais. A publicação de artigos científicos de Arqueologia em revistas internacionais também aumentou de forma constante e regular, resultado direto da ciência universitária brasileira. Arqueólogos com formação universitária nacional exerceram ou exercem funções em órgãos tão importantes como o World Archaeological Congress e a Union Internationale des Sciences
Pre-Historiques et Proto-Historiques, participam dos conselhos editoriais das mais prestigiosas revistas arqueológicas internacionais, atuam, de forma decisiva, nos rumos da disciplina em termos mundiais, apesar do caráter periférico do Brasil e, como consequência, da sua ciência. O sistema universitário brasileiro, portanto, tem sido fundamental para o desenvolvimento da Arqueologia no Brasil.

\section{Paulo Duarte e os combates pela diversidade no campo da Arqueologia brasileira}

As primeiras tentativas de defesa do patrimônio arqueológico brasileiro são anteriores à proposta da constituição de práticas arqueológicas produzidas no interior das academias. Ainda na década de 1920, Alberto Childe, presidente da Sociedade Brasileira de Belas Artes e chefe do Museu Nacional do Rio de Janeiro, propunha a nacionalização das "fontes culturais" (Bastos e Funari, 2008: 1128). A iniciativa não foi aprovada pelo Congresso, isso porque a ação poderia significar a necessidade da estatização de propriedades privadas; atitude nada interessante para os políticos - proprietários de terras e de outros bens no período.

A proposta de 1920 não assinalava a necessidade de uma divulgação ou de um programa educacional acerca dos patrimônios. Essa preocupação surgiu apenas em 1935, período anterior à fundação do SPHAN (Serviço do Patrimônio Histórico e Artístico Nacional). Naquele ano, Raimundo Lopes, arqueólogo maranhense, publicou um estudo sobre as fontes culturais nacionais e sobre a necessidade da elaboração de programas educacionais e de divulgação de informações sobre sítios arqueológicos.

As ações de Childe e de Lopes, intelectuais ligados à prática arqueológica, ainda que considerada amadora, e às discussões sobre as ações patrimoniais, indicam a existência de reflexões sobre os possíveis valores das materialidades e acerca das potencialidades das culturas materiais no que se refere à formação de identidades. É bastante claro, todavia, que tanto para Childe quanto para Lopes a preocupação nos usos e de- 
fesas dos patrimônios circunscrevia-se no desejo de criação de uma única identidade nacional.

As questões colocadas por esses autores faziam parte de contextos em que a configuração da identidade do povo brasileiro estava no centro dos debates intelectuais no país. Muitos humanistas se perguntavam "somos o que fomos?" Onde estaria nossa herança cultural? O que causou a diferença entre a "nossa cultura" e a "cultura européia"? Com o que nos parecemos? Almejava-se uma explicação para o funcionamento da cultura brasileira e os elementos que diferenciaram o país das nações do Velho Mundo (Tuna, 2000, p.21).

Com o final da Segunda Guerra Mundial, e com as evidenciações das atrocidades dos extermínios cometidos no conflito, as questões das diferenças humanas e culturais tornaram-se, em um contexto acadêmico, menos importantes do que a defesa de suas semelhanças. Neste viés, o humanista Paulo Duarte (1899-1984) apresentou novas possibilidades para a Arqueologia Brasileira e, em especial, para a construção de uma Arqueologia inserida no espaço universitário.

Duarte foi um participante ativo na fundação da Universidade de São Paulo (1934), estando, portanto, inserido no cerne das discussões referentes ao que se idealizava para a constituição e funcionamento de um grande espaço acadêmico. Para construir a USP, o intelectual, junto com um expressivo grupo de intelectuais brasileiros e estrangeiros, pesquisou diversos modelos de universidades européias e americanas. Com a USP instaurada, Duarte partiu para outros projetos ligados à proposta da pesquisa científica e aberta à sociedade como um todo.

Em 1945, com o final do Governo Vargas, Paulo Duarte conquistou a criação do Instituto de Pré-História; inicialmente dedicado ao estudo dos sambaquis. Para o humanista, a defesa dos sambaquis e dos vestígios arqueológicos de grupos indígenas era uma forma de valorizar o passado e o presente do país. Para ele, a identidade nacional não poderia ser formada apenas por grandes materialidades da elite branca e católica brasileira. Ao contrário, a identidade nacional deveria ser formada a partir da fusão de memórias daqueles que até então estavam silenciados: os indígenas, os sertanejos, os operários, entre outros.

Duarte não descartava o papel das elites e daquilo que ele considerava como cultura erudita para a formação do povo brasileiro. Para o humanista, era imperativo o domínio sobre a erudição e principalmente o divulgar desta erudição para a construção daquilo que ele imaginava ser o grande Brasil. A cultura e o conhecimento, para ele, produziam um grande povo (Backs 2010). Apesar de uma postura conservadora sobre o próprio conceito de identidade nacional, Duarte inovava ao defender a inserção de elementos tradicionalmente não considerados eruditos como sendo também parte constituinte do Brasil.

Nesta proposta, a criação de espaços acadêmicos - de ensino e pesquisa - era elementar para a construção do país. Apesar de dedicar-se aos estudos do passado histórico e arqueológico brasileiro, Duarte não se restringiu a esse campo de ação. Ele participou ativamente da fundação do Instituto Paulista de Oceanografia. Tratava-se de uma tentativa de criação de outros espaços de pesquisa livres de relações de poderes silenciadoras (Mendes 1994). Exatamente pela defesa da liberdade, e pelos perigos políticos representados pela escolha de Adhemar de Barros, como chefe do Governo do Estado, em 1962, tanto o Instituto de Pré-História como o Instituto Paulista de Oceanografia passaram a ser vinculadas à Universidade de São Paulo. Por questões políticas, formalizava-se a Arqueologia Universitária.

Vinculado à Universidade, o intelectual se tornou um combatente das relações de poderes marcadas pelos "apadrinhamentos" (e não vinculadas ao mérito pessoal) e do provincianismo cristalizado nas instituições públicas e privadas do país. Sua crítica, sempre ácida, o colocou em inúmeros confrontos com reitores e outros professores da USP. Mas seus embates não se constituíam de forma isolada.

Em meio a trincheiras políticas, Duarte conseguiu participar da elaboração da Lei de Proteção Patrimonial (lei 3924/61); em voga na atualidade. Seu relacionamento com intelectuais franceses permitiu a vinda ao Brasil de inúme- 
ros professores e arqueólogos daquele país. Ao mesmo tempo, tornou-se possível a ida de arqueólogos brasileiros para a França (como é o caso de Niéde Guidon). Ao lado de cientistas como Oswaldo Rodrigues Cabral, do Instituto de Antropologia da Universidade Federal de Santa Catarina - UFSC, Duarte participou ativamente das denúncias sobre a dilapidação do patrimônio arqueológico nacional (Funari e Silva, 2007). Seu engajamento político e social pavimentou caminhos para a profissionalização da Arqueologia brasileira e para a criação de inúmeras instituições museológicas instaladas no país.

Com a instalação da ditadura militar no Brasil, e com o simultâneo enrijecimento dos sistemas de delação e punição próprios à ditadura, Duarte teve sua aposentadoria compulsória decretada no ano de 1969; mesmo afastado da Universidade, continuou a agir na defesa da Universidade livre, do patrimônio nacional e, em especial, do patrimônio arqueológico. É importante ressaltar que Paulo Duarte é apenas um entre outros nomes que se dedicaram às pesquisas acadêmicas responsáveis. Infelizmente, assim como Paulo Duarte, muitos destes nomes foram apagados pelas memórias oficiais que respondem, sempre, às escolhas políticas.

A Arqueologia Universitária também continuou a existir durante a ditadura militar. Todavia, assim como o resto da sociedade brasileira, estava submetida a políticas e escolhas específicas dos governantes e de seus aliados. Questões relativas à identidade nacional continuavam a ser indagadas, mas, por ora, sob forte influência norte-americana (espaço antes ocupado majoritariamente pelos franceses).

A liberdade da realização da pesquisa científica, e a inerente possibilidade do debate acadêmico, só voltaram ao cenário político-acadêmico brasileiro após 1985. Diferente do que havia acontecido nos contextos dos anos de 1920 e 1930, representados por Childe e Lopes, ou das décadas de 1940 a 1960, expressas nas lutas de Paulo Duarte, a abertura política do país foi acompanhada pela elaboração de legislações estaduais de proteção dos sítios, monumentos e coleções arqueológicas (Bastos e Funari, 2008:1129), bem como pela reinauguração das discussões sobre a própria epistemologia da Arqueologia. O Brasil não estava sozinho nos novos debates constituídos dentro e fora das academias. Em 1986, era fundado o World Archaeological Congress, que passaria a defender a interligação entre escolhas realizadas no âmbito da ciência arqueológica e as múltiplas esferas políticas (Funari 2006).

Com este movimento do reascender da liberdade, assistimos a uma explosão do desenvolvimento de teses e dissertações, de publicação de livros e de práticas de arqueológicas variadas. No Brasil, em especial, participamos ativamente das discussões e da constituição dos cursos de graduação em Arqueologia, das investidas pela regulamentação da profissão de Arqueólogo e da busca pela pluralização daquilo que é considerado patrimônio e digno de inclusão nas memórias nacionais (temos como exemplo o recente reconhecimento dos lugares sagrados do Alto-Xingu como patrimônio cultural do Brasil). ${ }^{2}$

Não se trata apenas da inauguração de uma diversidade temática, mas também da consolidação de uma pluralidade de opções teóricas de arqueologia. Hoje, é possível escolher contextos específicos de falas. E, essa diversidade, permite o embate, o diálogo e a criação. Permite o reconhecimento do caráter eminentemente político das práticas arqueológicas. Neste viés, não se trata apenas de realizar uma pesquisa científica. Ao contrário, a realização da pesquisa Arqueológica Universitária deve ser constituída de forma responsável e dialogada com os mais variados públicos. A Arqueologia Universitária deve se abrir aos múltiplos contextos em que está inserida, tornando-se, inquestionavelmente, ética, livre e política.

\section{Agradecimentos}

Agradecemos a Lúcio Menezes Ferreira, Glaydson José da Silva. Mencionamos o apoio institucional da FAPESP, CNPq, UNICAMP e UNIFESP. A responsabilidade pelas idéias restringe-se aos autores.

(2) http://portal.iphan.gov.br/portal/montarDetalheConteudo.do? $\mathrm{id}=15201 \&$ sigla $=$ Noticia\& retorno=detalheNoticia 
FUNARI, P.P.A.; CARVALHO, A.V. Universities, Archaeology and Paulo Duarte.

R. Museu Arq. Etn., São Paulo, n. 22: 89-96, 2012.

\begin{abstract}
This article aims to analyze the trajectory of the academic Archaeology in Brazilian Universities from an institutional perspective of the State of São Paulo. Choosing an externalist view of the history of science, one that insets science itself into a wider social context, we will discuss: the University of São Paulo foundation and the institutionalization of intellectual relations with France in the 1930s and 1940s; the work of Paul Duarte, Brazilian humanist, responsible, among other accomplishments, for the creation of the Institute of Prehistory ; the military coup and its aftermath on university's Archaeology; and, at last, the political democratization in the 1980s and the insertion of Brazilian researches in the international arena.
\end{abstract}

Keywords: Academic Archaeology, History of Science and Paulo Duarte.

\title{
Referências bibliográficas
}

CARVALHO, A. V.; SANABRIA, I. S. B.

2012 "Paulo Duarte e os Combates pelos Patrimônios Plurais no Brasil”. In: Lúcio Menezes Ferreira; Maria Letícia Mazzucchi Ferreira; Mónica B. Rotman. (Org.). Patrimônio cultural no Brasil e na Argentina: estudo de casos. São Paulo: Annablume Editora.

BASTOS, R. L.; FUNARI, P. P. A.

2008 Public archaeology and management of the Brazilian archaeological-cultural heritage. In: Helaine Silverman; William H. Isbell. (Org.). Handbook of South American Archaeology. 1 ed. New York: Springer, v. 1, p. 1127-1133.

FERREIRA, L. M.

2005 Footsteps of American Race: Archaeology, Ethnography and Romanticism in Imperial Brazil. In: Pedro Paulo Abreu Funari; Andrés Zarankin; Emily Stovel. (Org.). Global Archaeology Theory: Contextual Voices and Contemporary Thoughts. New York: Springer, p. 137-156.

FUNARI, P. P. A.

1994 Paulo Duarte e o Instituto de Pré-História. Idéias: Campinas, v. 1, n. 1, p. 155-179.
FUNARI, P.P.A.

2002 Class interests in Brazilian archaeology. Boletín de Antropología Americana. New York, v. 6, n. 3, p. 209-216.

FUNARI, P.P.A.

2006 "The world archaeological congress from a critical and personal perspective”. Archaeologies. Volume 2, Number 1, 73-79.

FUNARI, P. P. A.; MENEZES, L.

2006 A social history of Brazilian archaeology: a case study. Bulletiin of the History of Archaeology, v. 16, p. 18-27.

FUNARI, P. P. A.; SILVA, G. J.

2007 Nota de Pesquisa sobre o Projeto de Pesquisa do Acervo de Arqueologia e Patrimônio de Paulo Duarte 06/03/2007. História e-História, v. 2007, p. 1-25.

MENDES, E. PAULO DUARTE

1994 Estudos Avançados. vol.8 no.22 São Paulo Sept./Dec.

TUNA, G. H

2000 Gilberto Freyre: entre tradição $\mathcal{E}$ ruptura. São Paulo: Cone Sul. 